\title{
AUTHOR INDEX \\ TO
}

\section{MATHEMATICAL PROCEEDINGS}

\author{
VOLUMES 91 TO 100 \\ (1982-1986)
}

CAMBRIDGE

1987 


\section{PREFACE}

The first cumulative index to the Proceedings of the Cambridge Philosophical Society was published in 1961 and entitled Author Index to Proceedings of the Cambridge Philosophical Society Volumes 1 to 50 (1843-1954), and Transactions of the Cambridge Philosophical Society Volumes 1 to 23 (1822-1928). An Index covering the Proceedings Volumes 51 to 60 (1955-1964) was published in 1967 and one covering Volumes 61 to $70(1965-1971)$ in 1972.

An index covering the Proceedings Volumes 71-76 (1972-1974) and, after the change of title, the Mathematical Proceedings Volumes 77 to 80 (1975-1976) was published in 1977. The index covering volumes 81-90 (1977-1981) was published in 1982.

This present Index covers the Mathematical Proceedings Volumes 91 to 100 (19821986). 


\section{INDEX OF AUTHORS}

Al-Hussaini, A. N. \& Elliot, R. J. Semimartingales and the empirical distribution. 96 (1984) $167-171$

AL-RAShed, A. M. \& DARST, R. B. Best $L_{\infty}$-approximation of measurable, vector-valued functions. $96(1984) 477-481$

ALDous, D. J. Self-intersections of random walks on discrete groups. 98 (1985) 155-177

Allenby, R. B. J. T. \& TANG, C. Y. Residual finiteness of certain 1-relator groups: extensions of results of Gilbert Baumslag. 97 (1985) 225-230

Allison, D. On square values of quadratics. 99 (1986) 381-383

ALPERN, S. Search for point in interval, with high-low feedback. 98 (1985) 569-578

ALvis, D. \& Lusztig, G. On Springer's correspondence for simple groups of type $E_{n}(n=6,7,8)$ 92 (1982) 65-78

Anderson, W. J. \& MathaI, A. M. Various representations of a generalized hypergeometric function through statistical techniques. 96 (1984) 325-330

Antman, S. S. \& CaldDerer, M. C. Asymptotic shapes of inflated noncircular elastic rings. 97 (1985) 357-379

Asymptotic shapes of inflated spheroidal nonlinearly elastic shells. 97 (1985) 541-549

Anyanwu, D. U. Langer's method for a second order linear ordinary differential equation with a double pole. 91 (1982) 111-118

Apps, A. B. Boolean powers of groups. 91 (1982) 375-395

ARCHBOLD, R. J. Approximating maps and exact $C^{*}$-algebras. 91 (1982) 285-289

Argyros, S. A. \& Tsarpalias, A. Isomorphic embeddings of $l_{1}(\Gamma)$ into subspaces of $C(\Omega)^{*}$. 92 (1982) 251-262.

Arthan, R. D. Localization of stable homotopy rings. 93 (1983) 295-302

Arthurs, A. M. \& Walsh, G. R. On Hammersley's minimum problem for a rolling sphere. 99 (1986) 529-534

Atanackovic, T. M. \& DJUkic, DJ. S. An extremum variational principle and error estimate procedure for $q^{\mathrm{IV}}=f(q, x)$. $92(1982) 307-316$

Atkin, C. J. A note on the algebra of Poisson brackets. 96 (1984) 45-60

BAE, J. S. \& CHоI, S. K. A note on $k$-uniformly convex spaces. 97 (1985) 489-490

BAGLEY, R. W. \& YANG, J.S. Semidirect products of central groups and groups with equal uniformities. $92(1982) 239-241$

BAKER, R. C. \& HaRman, G. Unbalanced quadratic residues and non-residues. 98 (1985) 9-17

BaLANDA, K. P. Maximally almost disjoint families of representing sets. 93 (1983) 1-7

BALL, J. M. \& SchaEFFer, D. G. Bifurcation and stability of homogeneous equilibrium configurations of an elastic body under dead-load tractions. 94 (1983) 315-339

Banaschewski, B. \& BhUtani, K. R. Boolean algebras in a localic topos. 100 (1986) 43-55

BĂ inică, C. \& Putinar, M. On complex vector bundles on rational threefolds. 97 (1985) 279-288

BARbour, A. D. Poisson convergence and random graphs. 92 (1982) 349-359

Barbour, A. D. \& Hall, P. On the rate of Poisson convergence 95 (1984) 473-480

BARNETT, C. \& Lyons, T. Stopping non-commutative processes, 99 (1986) 151-161

Barnett, C., Streater, R. F. \& Wilde, I. F. Stochastic integrals in an arbitrary probability gauge space 94 (1983) 541-551

Baskan, T. \& MACBEATh, A. M. Centralizers of reflections in crystallographic groups. 92 (1982) $79-91$

Baston, V. J. \& Bostock, F. A. A High-Low search game on the unit interval. 97 (1985) 345-348

BatTy, C. J. K. Some properties of maximal measures on compact convex sets. 94 (1983) 297-305

Topologies and continuous functions on extreme points and pure states. 98 (1985) 501-511

Batmslag, G. Free subgroups of certain one-relator groups defined by positive words. 93 (1983) $247-251$

BaXter, L. A. Continuum structures. II. 99 (1986) 331-338 
BAYER-FLUCKiger, E. Cancellation of hyperbolic $\epsilon$-hermitian forms and of simple knots. 98 (1985) 111-115

Bayer-Fluckiger, E. \& Stoltzfus, N. W. Indecomposable knots and concordance. 93 (1983) 495-502

Beardon, A. F. \& Wilker, J. B. The norm of a Möbius transformation. 96 (1984) 301-308

BECKER, H. Analytic sets from the point of view of compact sets. 99 (1986) 1-4

BEN-IsRaEL, A. Generalized inverses of matrices: a perspective of the work of Penrose. 100 (1986) 407-425

Bennett, D. P., Brown, R. W., Stansfield, S. E., Stroughair, J. D. \& Bona, J. L. The stability of internal solitary waves $94(1983) 351-379$

Berman, S. M. Multiple images of stochastic processes. 94 (1983) 183-188

Bernau, S. J. Additivity and superadditivity in $L_{p}$-spaces 100 (1986) $133-136$

Bhutani, K. R. \& Banachewski, B. Boolean algebras in a localic topos. 100 (1986) 43-55

Bingham, N. H. \& Tenenbaum, G. Reisz and Valiron means and fractional moments. 99 (1986) $143-149$

BLEILER, S. A. A note on unknotting number. 96 (1984) 469-471

BLows, T. R. \& LlOYD, N. G. The number of small-amplitude limit cycles of Liénard equations. 95 (1984) 359-366

Bolton, J. Isometric immersions into manifolds without conjugate points. 92 (1982) 243-250

Bombal, F. \& Cembranos, P. Characterization of some classes of operators on spaces of vector-valued continuous functions. 97 (1985) 137-146

Bona, J. L., Bennett, D. P., Brown, R. W., Stansfield, S. E. \& Strovghair, J. D. The stability of internal solitary waves. 94 (1983) $351-379$

Bonahon, F. Ribbon fibred knots, cobordism of surface diffeomorphisms, and pseudo-Anosov diffeomorphisms. 94 (1983) 235-251

Bor, H. On two summability methods. 97 (1985) 147-149

Borcea, C. Families of smooth hypersurfaces on certain compact homogeneous complex manifolds. 93 (1983) 315-321

Bostock, F. A. \& Baston, V.J. A High-Low search game on the unit interval. 97 (1985) 345-348

Bотт, R. T. Singularity of generalised Riesz products. 93 (1983) 335-338

BOYER, S. Shake-slice knots and smooth contractible 4-manifolds. 98 (1985) 93-106

On the non-realizability of certain 3-manifolds by Dehn surgery. 99 (1986) 103-106

Brennan, J. E. The Cauchy integral and analytic continuation. 97 (1985) 491-498

Brodmann, M. A lifting result for local cohomology of graded modules. 92 (1982) 221-229

BRook Es, C. J. B. Ideals in group rings of soluble groups of finite rank. 97 (1985) 27-49

Brown, G. \& Dooley, A. H. Ergodic measures are of weak product type. 98 (1985) 129-145

Brown, G., Karanikas, C. \& Williamson, J. H. The asymmetry of $M_{0}(G) .91(1982) 407-433$

Brown, G. \& Moran, W. Probability measures with trivial Stam groups. 91 (1982) 477-484

Brown, M. L. Defective big Cohen-Macaulay modules. 93 (1983) 253-257

On 2-dimensional local rings with Artin's approximation property. 94 (1983) 35-52

On automorphisms of unique factorization domains. 98 (1985) 427-428

Brown, R. W., Stansfield, S. E., Stroughair, J. D., Bennett, D. P. \& Bona, J. L. The stability of internal solitary waves. 94 (1983) 351-379

Brown, T. C., Cartwright, D. I. \& Eagleson, G. K. Characterizations of invariant distributions. 97 (1985) 349-355

Brownawell, W. D. \& Masser, D. W. Vanishing sums in function fields. 100 (1986) 427-434

BRUCE, J. W. Wavefronts and parallels in Euclidean space. 93 (1983) 323-333 Envelopes and characteristics. 100 (1986) 475-492

BRyce, R. A. \& Cossey, J. Subgroup closed Fitting classes are formations. 91 (1982) 225-258 Corrigenda: Subgroup closed Fitting classes 91 (1982) 343

Buoncristiano, S. \& Hacon, D. Resolving homologies in BPL and PL characteristic numbers. 93 (1983) 263-269

Burkill, H. \& Rennie, B. C. Almost periodic generalized functions. 94 (1983) 149-166

BURN, R. P. Finite Bol loops. III. 97 (1985) 219-223

Corrigenda: Finite Bol loops. III. 98 (1985) 381

Buschman, R. G. \& Srivastava, H. M. Series identities and reducibility of Kampé de Fériet functions. 91 (1982) $435-440$ 
Byrne, A. \& Love, E. R. Real inversion theorems for generalized Stieltjes transforms. II. 92 (1982) 275-291

Calderer, M. C. \& Antman, S. S. Asymptotic shapes of inflated noncircular elastic rings. 97 (1985) 357-379

Asymptotic shapes of inflated spheroidal nonlinearly elastic shells. 97 (1985) 541-549

CÁmera, G. A. Unbounded subharmonic functions bounded in one tract. 98 (1985) 327-341

Canarutto, D. \& Dodson, C. T. J. On the bundle of principal connections and the stability of $b$-incompleteness of manifolds. 98 (1985) 51-59

Cantriun, F., Crampin, M. \& Sarlet, W. Higher-order differential equations and higher-order lagrangian mechanics. 99 (1986) 565-587

Carey, A. L. \& Moran, W. Characters of nilpotent groups. 96 (1984) 123-137

CARreras, F. J. Linear invariants of Riemannian almost product manifolds. 91 (1982) 99-106

Cartwright, D. I., Eagleson, G. K. \& Brown, T. C. Characterizations of invariant distributions. 97 (1985) 349-355

Cassels, J. W. S. Mordell's finite basis theorem revisited. 100 (1986) 31-41

Cembranos, P. \& Bombal, F. Characterization of some classes of operators on spaces of vector-valued continuous functions. 97 (1985) 137-146

Chatters, A. W. Non-commutative unique factorization domains. 95 (1984) 49-54

Cheng, S.-S. \& Huang, Y.-T. Optimal intersections of plane lattice points with vertical and horizontal straight lines. 94 (1983) 381-388

Chetwynd, A. G. \& Hilton, A. J. W. Star multigraphs with three vertices of maximum degree. 100 (1986) 303-317

ChoI, S. K. \& BAE, J. S. A note on k-uniformly convex spaces. 97 (1985) 489-490

Clifford, P. \& Green, N. J. B. Distances in Gaussian point sets. 97 (1985) 515-524

Cochran, J. A. \& LeE, C.-S. Inequalities related to Hardy's and Heinig's. 96 (1984) 1-7

Cochra , T. D. A topological proof of Stallings' theorem on lower central series of groups. 97 (1985) 465-472

Cohen, F. R. \& Neisendorfer, J. A. Note on desuspending the Adams map. 99 (1986) 59-64

Cohen, J. E. Connectivity of finite anisotropic random graphs and directed graphs. 99 (1986) $315-330$

CoHen, P. On the coefficients of the transformation polynomials for the elliptic modular function. 95 (1984) $389-402$

СонN, H. On a class of non-homogeneous Markov chains. 92 (1982) 527-534

Cohn, P. M. \& Schofield, A. H. On the law of nullity. 91 (1982) 357-374

Collins, D. J. \& Perraud, J. Cohomology and finite subgroups of small cancellation quotients of free products. $97(1985) 243-259$

Conrey, J. B. \& Ghosh, A. A simpler proof of Levinson's theorem. 97 (1985) 385-395

Conway, J. H. \& Sloane, N. J. A. The Coxeter-Todd lattice, the Mitchell group, and related sphere packings. 93 (1983) 421-440

Cooke, R. M., Keane, M. \& Moran, W. An elementary proof of Gleason's theorem. 98 (1985) 117-128

Coppel, W. A. Sarkovskii-minimal orbits. 93 (1983) 397-408

Cordier, J.-M. \& Porter, T. Vogt's theorem on categories of homotopy coherent diagrams. 100 (1986) 65-90

Cossey, J. \& BRYCE, R. A. Subgroup closed Fitting classes are formations. 91 (1982) 225-258 Corrigenda: Subgroup closed Fitting classes 91 (1982) 343

Cox, D. C. Note on a martingale inequality of Pisier. 92 (1982) 163-165

Cox, J. T. \& DurReTT, R. Oriented percolation in dimensions $d \geqslant 4$ : bounds and asymptotic formulas. 93 (1983) 151-162

Crampin, M. Generalized Bianchi identities for horizontal distributions 94 (1983) 125-132

Crampin, M., McCarthy, P. J. \& Stephenson, W. Graphs in the plane invariant under an area preserving linear map and general continuous solutions of certain quadratic functional equations. 97 (1985) 261-278

Crampin, M., Sarlet, W. \& Cantrisn, F. Higher-order differential equations and higher-order lagrangian mechanics. 99 (1986) 565-587

Crampin, M. \& Thompson, G. Affine bundles and integrable almost tangent structures. 98 (1985) 61-71 
Csörgö, S. \& Mason, D. M. Central limit theorems for sums of extreme values. 98 (1985) $\mathbf{5 4 7 - 5 5 8}$

Cuenca Mira, J. A. \& Rodriguez Palacios, A. Isomorphisms of $H^{*}$-algebras. 97 (1985) 93-99

Cusick, T. W. Finding fundamental units in cubic fields. 92 (1982) 385-389

Finding fundamental units in totally real fields. 96 (1984) 191-194

Dahmen, W., Micchelli, C. A. \& Smith, P. W. Asymptotically optimal sampling schemes for periodic functions. 99 (1986) 171-177

DaLEy, D. J. Infinite intensity mixtures of point processes. 92 (1982) 109-114

Darst, R. B. \& AL-Rashed, A. M. Best $L_{\infty}$-approximation of measurable, vector-valued functions $96(1984) 477-481$

David, H. T., Werner, N. M. \& Dorea, C. C. Y. Uniform $\epsilon$-independence and the convergence in distribution of randomly indexed sequences. $96(1984) 533-542$

DAvies, E. B. A generation theorem for operators commuting with group actions. 96 (1984) 313-320

Davies, R. O. \& Tricot, C. A theorem about countable decomposability. 91 (1982) 457-458

Davis, D. M. \& Mahowald, M. The spectrum $(P \wedge b o)_{-\infty} 96$ (1984) 85-93

Dawson, R. J. MacG. On the mobility of bodies in $\mathbb{R}^{n}$. 98 (1985) 403-412

Corrigenda: On the mobility of bodies in $\mathbb{P}^{n}$. 99 (1986) 377-379

De Brabanter, M. Decomposition theorems for certain $C^{*}$-crossed products. 94 (1983) 265-275

De Guzman, I. P. Structure theorems for alternative $H^{*}$-algebras. 94 (1983) 437-446

Dehesa, J. S. \& Galvez, F. J. Novel properties of Fibonacci and Lucas polynomials. 97 (1985) $159-164$

Deutsch, E. Lower bounds for the Perron root of a nonnegative irreducible matrix. 92 (1982) 49-54

Dicks, W. Homogeneous elements of free algebras have free idealizers. 97 (1985) 7-26

Dierolf, P. On $A-\Omega$ extendable distributions. 99 (1986) 135-142

Dikshiт, H. P. \& Олна, A. On convergence and quasiconformality of complex planar spline interpolants. 99 (1986) 347-356

Dilworth, S.J. The dimension of Euclidean subspaces of quasi-normed spaces. 97 (1985) $311-320$

Complex convexity and the geometry of Banach spaces. 99 (1986) 495-506

Dixon, P. G. \& Drury, S. W. Unitary dilations, polynomial identities and the von Neumann inequality. 99 (1986) 115-122

Djukic, DJ. S. \& Atanackovic, T. M. An extremum variational principle and error estimate procedure for $q^{1 \mathrm{v}}=f(q, x) . \quad 92(1982) 307-316$

Dodson, C. T. J. \& CanarutTo, D. On the bundle of principal connections and the stability of $b$-incompleteness of manifolds. 98 (1985) $51-59$

Dold, A. Ramified coverings, orbit projections and symmetric powers. 99 (1986) 65-72

Donkin, S. On the Hopf algebra dual of an enveloping algebra. 91 (1982) 215-224

On Ext' for semisimple groups and infinitesimal subgroups. 92 (1982) 231-238

A note on decomposition numbers for general linear groups and symmetric groups. 97 (1985) 57-62

Donnelly, P. The transient behaviour of the Moran model in population genetics. 95(1984) $349-358$

Donnelly, P. \& Welsh, D.J.A. Finite particle systems and infection models. 94 (1983) 167-182

Dooley, A. H. \& Brown, G. Ergodic measures are of weak product type. 98 (1985) 129-145

Dooley, A. H. \& Rice, J. W. Contractions of rotation groups and their representations. 94 (1983) 509-517

Dor, L. E. Corrigenda: Some inequalities for martingales and applications to the study of $L_{1}$. 91 (1982) 343

Dorea, C. C. Y., David, H. T. \& Werner, N. M. Uniform $\epsilon$-independence and the convergence in distribution of randomly indexed sequences. 96 (1984) 533-542

Drury, S. W. \& Drxon, P. G. Unitary dilations, polynomial identities and the von Neumann inequality. 99 (1986) 115-122

DruRy, S. W. \& Marshall, B. P. Fourier restriction theorems for curves with affine and Euclidean arclengths. 97 (1985) $111-125$ 
DurretT, R. \& Cox, J. T. Oriented percolation in dimensions $d \geqslant 4$ : bounds and asymptotic formulas. 93 (1983) 151-162

DYE, R. H. Osculating hyperplanes and a quartic combinant of the nonsingular model of the Kummer and Weddle surfaces. 92 (1982) 205-220

Eagleson, G. K., Brown, T. C. \& Cartwright, D. I. Characterizations of invariant distributions. 97 (1985) 349-355

Eastwood, M. G. The generalized Penrose-Ward transform. 97 (1985) 165-187

EAstwood, M. G. \& ToD, K. P. Edth - a differential operator on the sphere. 97 (1982) 317-330

Edmonds, A. L. \& Ewing, J. H. Surface symmetry and homology. 99 (1986) 73-77

Edwards, C. M. \& RÜtTimans, G. T. On the facial structure of the unit balls in a GL-space and its dual. 98 (1985) 305-322

EDWards, D. A. A short proof of a theorem of Machado. 99 (1986) 111-114

EggLeston, H. G. Vector sums of Valentine convex sets. 92 (1982) 17-19

ELIAS, J. On the analytic equivalence of curves. 100 (1986) 57-64

Eluiot, R. J. \& Al-Hussarni, A. N. Semimartingales and the empirical distribution. 96 (1984) 167-171

EмвRеснтs, P. \& Oмеу, E. On subordinated distributions and random record processes. 93 (1983) 339-353

EPLETt, W. J. R. A fixed point approach to local minimax theory. 99 (1986) 339-346

Erbe, L. H., Sree Hari Rao, V. \& Seshagiri Rao, K. V. V. Non-oscillation and asymptotic properties for a class of forced second-order nonlinear equations. 95 (1984) 155-163

ERDEM, S. Harmonic maps from surfaces into pseudo-Riemannian spheres and hyperbolic spaces. 94 (1983) 483-494

ERLE, D. Topological Hopf bifurcation in the plane. 93 (1983) 113-119

Evans, S. N. On the Hausdorff dimension of Brownian cone points. 98 (1985) 343-353

Everest, G. R. Diophantine approximation and Dirichlet series. 97 (1985) 195-210

Evertse, J. H. \& Silverman, J. H. Uniform bounds for the number of solutions to $Y^{n}=f(X)$. 100 (1986) 237-248

Ewing, J. H. \& Edmonds, A. L. Surface symmetry and homology. 99 (1986) 73-77

FaLCONER, K. J. Growth conditions on powers of Hermitian elements. 92 (1982) 115-119

Corrigenda: Growth conditions on powers of Hermitian elements. 95 (1984) 513-515

Random fractals. 100 (1986) 559-582

Fidal, D. L. The existence of sextactic points. 96 (1984) $433-436$

Fidal, D. L. \& Giblin, P. J. Generic 1-parameter families of caustics by reflexion in the plane. 96 (1984) 425-432

FisheL, B. Generalized translations associated with an unbounded self-adjoint operator. 99 (1986) 519-528

Fishel, B. \& ZAHReddine, Z. Boundary conditions and reducibility of differential operators. 96 (1984) 549-553

FLAJOLET, P. \& OdLyzKo, A. M. Limit distributions for coefficients of iterates of polynomials with applications to combinatorial enumerations. 96 (1984) 237-253

Flapan, E. A prime strongly positive amphicheiral knot which is not slice. 100 (1986) 533-537

Fleming, D. J. \& Giarrusso, D. M. Topological decompositions of the duals of locally convex operator spaces. $93(1983) 307-314$

Förster, P. Homomorphs and wreath product extensions. 92 (1982) 93-99

Fountain, J. \& Petrich, M. Brandt semigroups of quotients. 98 (1985) 413-426

FouRIE, J. H. On $A$-Mackey convergence in locally convex spaces. 96 (1984) 495-500

Fourie, J. H. \& Ruckle, W. H. Projections and embeddings of locally convex operator spaces and their duals. 96 (1984) 321-323

Fournelle, T. A. Torsion in semicomplete nilpotent groups. 94 (1983) 191-202

Fraenkel, A. S. \& TASSA, U. Strategies for compounds of partizan games. 92 (1982) 193-204

Friedlander, E. M. \& Mislin, G. Locally finite approximation of Lie groups. II. 100 (1986) 505-517

Friedlander, F. G. Corrigenda: Multi-valued solutions of the wave equation. 95 (1984) 187 
Friedlander, J. B. Sifting short intervals. 91 (1982) 9-15

Sifting short intervals II. $92(1982) 381-384$

Friedman, H. M. \& Ščedrov, A. On the quantificational logic of intuitionistic set theory. (1986) 5-10

Furusawa, H. The Hausdorff dimension of limit sets of Fuchsian groups of the type $(g ; m)$. 98 (1985) 147-154

Galambos, J. \& Kátai, I. A note on random walks in multidimensional time. 99 (1986) 163-170

GALDI, G. P., Knops, R. J. \& Rionero, S. Uniqueness and continuous dependence in the linear elastodynamic exterior and half-space problems 99 (1986) 357-366

Gallowa, G. J. Curvature, causality and completeness in space-times with causally complete spacelike slices. 99 (1986) 367-375

Galvez, F. J. \& Dehesa, J. S. Novel properties of Fibonacci and Lucas polynomials. 97 (1985) $159-164$

Garling, D. J. H. Another 'short' proof of the Riesz representation theorem. 99 (1986) 261-262

GÁspár, Zs. \& TARNAI, T. Improved packing of equal circles on a sphere and rigidity of its graph. 93 (1983) 191-218

GAUDRY, G. I. \& PINI, R. Bernstein's theorem for compact, connected Lie groups. 99 (1986) 297-305

Gersten, S. M. \& Howie, J. Counterexamples to a conjecture about spherical diagrams. 100 (1986) 539-543

Ghahramani, F. \& Medgalchi, A. R. Compact multipliers on weighted hypergroup algebras. 98 (1985) 493-500

Compact multipliers on weighted hypergroup algebras. II. 100 (1986) 145-149

Ghosh, A. \& Conrey, J. B. A simpler proof of Levinson's theorem. 97 (1985) 385-395

Giambalvo, V. \& Pengelley, D. J. The homology of MSpin. 95 (1984) 427-436

Giarrusso, D. M. \& Fleming, D. J. Topological decompositions of the duals of locally convex operator spaces. $93(1983) 307-314$

GibBoN, G. Intersection properties of functions on cardinals. 100 (1986) 265-280

Giblin, P. J. \& Fidal, D. L. Generic 1-parameter families of caustics by reflexion in the plane. 96 (1984) 425-436

Giblin, P. J. \& Hui, C. M. Specializations of complex quartic curves. 91 (1982) 171-181

Giblin, P. J. \& Soares, M. G. Recognizing singularities of surfaces in $\mathbb{C P}^{3}$. 91 (1982) 17-27

GILChrist, M. P. \& Sмiтh, M. K. Non-commutative UFD's are often PID's. 95 (1984) 417-419

GiLmovr, C. R. A. Realcompact spaces and regular $\sigma$-frames. $96(1984) 73-79$

Giotopoulos, S. A note on annihilator Banach algebras. 97 (1985) 101-106

Glass, A. M. W. Countable lattice-ordered groups. 94 (1983) 29-33

Glass, A. M. W., Saracino, D. \& Wood, C. Non-amalgamation of ordered groups. 95 (1984) 191-195

GLOBEVNIK, J. Norm preserving interpolation sets for polydisc algebras. 91 (1982) 291-303

Holomorphic maps of discs into balls of $l^{p}$-spaces. 99 (1986) 123-133

Godwin, H. J. A note on Cusick's theorem on units in totally real cubic fields. 95 (1984) 1-2

Explicit expressions for Sturm sequences. 100 (1986) 225-227

Goel, S. \& Vasudevan, R. Embedding of quasi-multipliers of a Banach algebra into its second dual. 95 (1984) 457-466

Gomez-Larra ̃̃ aga, J. C. Totally knotted knots are prime. 91 (1982) 467-472

González ACũ̃a, F. \& Short, H. Knot surgery and primeness. 99 (1986) 89-102

Goov, I. J. Corrigenda: A new formula for cumulants. 91 (1982) 343

Goodey, P. R. Homothetic ellipsoids. 93 (1983) 25-34

Goodman, F. M., Jorgensen, P. \& Peligrad, C. Smooth derivations commuting with Lie group actions. 99 (1986) 307-314

Gopalsamy, K. On the global attractivity in a generalized delay-logistic differential equation. 100 (1986) 183-192

Goswami, S. K. \& MANDaL, B. N. Scattering of surface waves obliquely incident on a fixed half immersed circular cylinder. 96 (1984) 359-369

GRÄBE, H.-G. A dualizing complex for Stanley-Reisner rings. 96 (1984) 203-212

Graham-Eagle, J. A new method for calculating eigenvalues with applications to gravitycapillary waves with edge constraints. $94(1983) 553-564$ 
Granville, A. J. Refining the conditions on the Fermat quotient. 98 (1985) 5-8

GRAY, B. Unstable families related to the image of $J$. 96 (1984) 95-113

On Toda's fibrations. 97 (1985) 289-298

Green, N. J. B, \& Clifford, P. Distances in Gaussian point sets. 97 (1985) 515-524

GrimmetT, G. R., Keane, M. \& Marstrand, J. M. On the connectedness of a random graph. 96 (1984) 151-166

Györi, E., Rothschild, B. \& Ruciśski, A. Every graph is contained in a sparsest possible balanced graph. 98 (1985) 397-401

Hacon, D. \& Buoncristiano, S. Resolving homologies in BPL and PL characteristic numbers. 93 (1983) 263-269

Hall, P. The order of the approximation to a Wiener process by its Fourier series. 92 (1982) $547-562$

Edgeworth expansion of the distribution of Stein's statistic. 93 (1983) 162-175

Limit theorems for sums of general functions of $m$-spacings. 96 (1984) 517-532

A tabular method for correcting skewness. 97 (1985) 525-540

Hall, P. \& Barbour, A. D. On the rate of Poisson convergence. 95 (1984) 473-480

HALL, R. R. On some theorems of Hurwitz and Sheil-Small. 100 (1986) 365-370

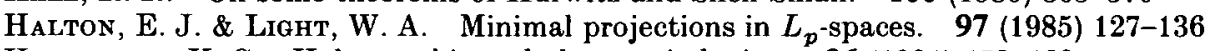

HANNABUSS, K. C. Holomorphic and abstract inducing. 96 (1984) 453-468

Haran, D. \& Lubotzky, A. Maximal abelian subgroups of free profinite groups. 97 (1985) 51-55

HARER, J. Representing elements of $\pi_{1} M^{3}$ by fibred knots. 92 (1982) 133-138

Harman, G. Diophantine approximation with square-free integers. 95 (1984) 381-388

Some theorems in the metric theory of diophantine approximation. 99 (1986) 385-393

HaRMAN, G. \& BAKER, R. C. Unbalanced quadratic residues and non-residues. 98 (1985) 9-17

Hartley, B. \& Shahabi Shojaei, M. A. Finite groups of matrices over division rings. 92 (1982) $55-64$

Finite quasisimple groups of $2 \times 2$ matrices over a division ring. 97 (1985) 415-420

HarveY, J. M. Categorical characterization of uniform hyperspaces. 94 (1983) 229-233

Hass, J. The geometry of the slice-ribbon problem. 94 (1983) 101-108

Hemmer, P. C. \& Hemmer, S. Recurrences in multidimensional arithmetic sequences. 93 (1983) 393-396

Hemmer, S. \& Hemmer, P. C. Recurrences in multidimensional arithmetic sequences. 93 (1983) 393-396

Henle, J. M. \& Mathias, A. R. D. Supercontinuity. 92 (1982) 1-15

Hennings, M. A. Fronsdal *-quantization and Fell inducing. 99 (1986) 179-188

Herrmann, M. \& Orbanz, U. On equimultiplicity. 91 (1982) 207-213

HewitT, E. \& KosHi, S. Orderings in locally compact abelian groups and the theorem of F. and M. Riesz. 93 (1983) 441-457

Higarns, J. R. Some orthogonal and complete sets of Bessel functions associated with the vibrating plate. 91 (1982) 503-515

Hildebrand, A. Multiplicative functions at consecutive integers. 100 (1986) 229-236

HiLl, R. Constitutive branching in elastic materials. 92 (1982) 167-181

On intrinsic eigenstates in plasticity with generalized variables. 93 (1983) 177-189

On a symbolic algebra for Hencky-Prandtl nets. 94 (1983) 341-350

On macroscopic effects of heterogeneity in elastoplastic media at finite strain. 95 (1984) 481-494

On the micro-to-macro transition in constitutive analyses of elasto-plastic response at finite strain $98(1985) 579-590$

Hillman, J. A. Topological concordance and $F$-isotopy. 98 (1985) 107-110

Hilton, A. J. W. \& ChETwynd, A. G. Star multigraphs with three vertices of maximum degree. 100 (1986) 303-317

HoAre, A. H. M. On groups with real valued length function. 95 (1984) 223-227

HoRváth, L. Strong laws for randomly indexed $U$-statistics. 98 (1985) 559-567

HowIE, J. Spherical diagrams and equations over groups. 96 (1984) 255-268

Howie, J. \& Gersten, S. M. Counterexamples to a conjecture about spherical diagrams. 100 (1986) 539-543

Howie, J. \& Pride, S. J. The word problem for one-relator semigroups 99 (1986) 33-44 
Huang, Y.-T. \& Cheng, S.-S. Optimal intersections of plane lattice points with vertical and horizontal straight lines. 94 (1983) 381-388

Huggins, R. M. \& ScotT, D. J. A law of the iterated logarithm for weakly exchangeable arrays. 98 (1985) 541-545

Hughes, M. C. Representations of complex imprimitive reflection groups. 94 (1983) 425-436

HUI, C. M. \& Giblin, P. J. Specialization of complex quartic curves. 91 (1982) 171-181

HuLme, A. A note on the magnetic scalar potential of an electric current-ring. 92 (1982) 183-191

Some applications of Maz'ja's uniqueness theorem to a class of linear water wave problems. 95 (1984) 165-174

Humphreys, J. F. Conjugacy classes of double covers of monomial groups. 96 (1984) 195-201

HUNT, G. W. \& Williams, K. A. J. On truncation of the structural potential function. 95 (1984) 495-510

Hurley, D. Note on uniform visibility manifolds. 98 (1985) 73-80

Hyyrö, S., Merikoski, J. K. \& Virtanen, A. Improving certain simple eigenvalue bounds. 99 (1986) 507-518

Ionescu, P. Generalized adjunction and applications. 99 (1986) 457-472

IsBeLL, J. R. A frame with no admissible topology. 94 (1983) 447-448

General function spaces, products and continuous lattices. 100 (1986) 193-205

Istrátgescu, V. I. \& Partington, J. R. On nearly uniformly convex and $k$-uniformly convex spaces. 95 (1984) 325-327

JACKson, D. A. Some one-relator semigroup presentations with solvable word problems.

99 (1986) 433-434

JAmES, G. D. On the minimal dimensions of irreducible representations of symmetric groups. 94 (1983) 417-424

JANECzko, S. Generating families for images of Lagrangian submanifolds and open swallowtails. 100 (1986) 91-107

$\mathrm{J}_{\mathrm{ANSON}}, \mathrm{S}$. Random trees in a graph and trees in a random graph. $100(1986) 319-330$

JECH, T. \& PRIKRY, K. Cofinality of the partial ordering of functions from $\omega_{1}^{-}$into $\omega$ under eventual domination. 95 (1984) 25-32

JEFFERIES, B. Egorov measurability and generator cores. 100 (1986) 137-143

Johnson, D. L. Towards a characterization of smooth braids. 92 (1982) 425-427

Johnson, F.E. A. Locally symmetric homology spheres and an application of Matsushima's formula. $91(1982) 459-466$

A homological criterion for the realizability of poly-Surface groups. 97 (1985) 89-92

A class of non-Kählerian manifolds. 100 (1986) 519-521

Johrson, K. W. Loop transversals and the centralizer ring of a permutation group. 94 (1983) $411-416$

Johnstone, P. T. Quotients of decidable objects in a topos. 93 (1983) 409-419

Jones, D. S. An exterior problem in elastodynamics. 96 (1984) 173-182

Jones, G. A. \& Soomro, K. D. On a theorem of Wielandt concerning simply primitive groups. 92 (1982) 419-423

Jones, J. D.S. \& WeGManN, S. A. Limits of stable homotopy and cohomotopy groups. 94 (1983) 473-482

Jorgensen, P., Peligrad, C. \& Goodman, F. M. Smooth derivations commuting with Lie group actions. 99 (1986) 307-314

Joshi, J. M. C. \& UPRETI, R. A sequence of Gamma-type approximation operators. 96 (1984) 119-121

JUPP, P. E. A Poincaré limit theorem for wrapped probability distributions on compact symmetric spaces. 95 (1984) 329-334

Characterization of matrix probability distributions by mean residual lifetime. $\quad 100(1986)$ 583-589

Kalinowski, M. W. \& Sewery Ński, M. Differential equation for Hermite-Bell polynomials. 91 (1982) 259-265

Kane, R. The cohomology of finite $H$-spaces as $U(M)$ algebras. III. 94 (1983) 461-471

KANETA, H. Note on propagation of classical waves. I. 98 (1985) 179-181

Note on propagation of classical waves. II. 98 (1985) 367-372 
Karanasios, S. Perturbation of a nest algebra module. 93 (1983) 303-306

KARANIKAS, C. S.I.P. measures on metrizable groups. 93 (1983) 511-518

Karanikas, C., Brown, G. \& Williamson, J. H. The asymmetry of $M_{0}(G) .91$ (1982) 407-433

Karanikas, C. \& Williamson, J. H. Norms and spectra for certain subalgebras of $M\left(G^{t}\right)$. 95 (1984) 109-122

KasSEM, S. E. Multipole expansions for two superposed fluids, each of finite depth. 91 (1982) 323-329

Wave source potentials for two superposed fluids, each of finite depth. $\quad 100(1986) 595-599$

Kátai, I. \& Galambos, J. A note on random walks in multidimensional time. 99 (1986) 163-170

KATZ, D. \& Ratliff, L. J. JR. Form rings and projective equivalence. 99 (1986) 447-456

Katz, E., Morris, S. A. \& Nickolas, P. Free subgroups of free abelian topological groups. 100 (1986) 347-353

Keane, M., Cooke, R. M. \& Moran, W. An elementary proof of Gleason's theorem. 98 (1985) $117-128$

Keane, M., Grimmett, G. R. \& Marstrand, J. M. On the connectedness of a random graph 96 (1984) 151-166

Kelly, D. G. \& Oxley, J. G. Asymptotic properties of random subsets of projective spaces. 91 (1982) 119-130

KHALIL, R. Best approximation in $L^{p}(I, X) .94(1983) 277-279$

KING, W. P. C. Semifinite traces on JBW-algebras. 93 (1983) 503-509

Kingman, J. F. C. Random variables with unsymmetrical linear regressions. 98 (1985) 355-365

KIRBY, D. Subrings of the first neighbourhood ring. II. 92 (1982) 35-39

KLUSCH, D. On the approximation of analytic functions in a strip. 97 (1985) 381-384

Knops, R. J., Rionero, S. \& Galdi, G. P. Uniqueness and continuous dependence in the linear elastodynamic exterior and half-space problems. 99 (1986) 357-366

Koвayashi', T. Note on almost complex structures on products of lens spaces. 96 (1984) 81-83

КолıмА, S. Bounding finite groups acting on 3-manifolds. 96 (1984) 269-281

КомJі́т, $P$. A continuous generalization of the transversal property. 95 (1984) 21-23

Koshi, S. \& HewitT, E. Orderings in locally compact abelian groups and the theorem of F. and M. Riesz. 93 (1983) 441-457

Kourouniotis, C. Deformations of hyperbolic structures. 98 (1985) 247-261

Kowalski, O. \& VANHECKE, L. Classification of five-dimensional naturally reductive spaces. 97 (1985) 445-463

KozLowski, A. Operations in Segal's cohomology. 95 (1984) 437-441

Kravvaritis, D. Nonlinear random equations with maximal monotone operators in Banach spaces. 98 (1985) 529-532

KROPHOLLER, P. H. A note on the cohomology of metabelian groups. 98 (1985) 437-445

KUнN, N. J. A Kahn-Priddy sequence and a conjecture of G. W. Whitehead. 92 (1982) 467-483

Corrigenda : A Kahn-Priddy sequence and a conjecture of G. W. Whitehead. 95 (1984) $189-190$

Kunn, N. J. \& Priddy, S. B. The transfer and Whitehead's conjecture. 98 (1985) 459-480

Kunen, K. \& Miller, A. W. Borel and projective sets from the point of view of compact sets. 94 (1983) 399-409

KUPKA, J. G. Two limit theorems for ergodically regenerated stochastic processes. 93 (1983) $519-536$

Kuttner, B. Absolute summability functions for Hausdorff methods. 91 (1982) 51-56 On non-uniqueness of the order of saturation. II. 96 (1984) 115-117

Kuttiner, B. \& Maddox, I. J. Lacunary theorems for Cesàro means. 93 (1983) 231-235

Kuttner, B., Mohapatra, R. N. \& Sahney, B. N. Saturation results for a class of linear operators. $94(1983) 133-148$

KutTNer, B. \& SukLa, I. L. On $(\mathscr{D}, h(n))$ summability methods. 97 (1985) 189-193

KWASIK, S. On realization of Whitehead torsion. 98 (1985) 271-273

KWASIK, S. \& VOGEL, P. On invariant knots. 96 (1984) 473-475

KwEE, B. On the converse of absolute Abel summability. 91 (1982) $453-456$

LANDWEBER, P. S. A survey of bordism and cobordism. 100 (1986) 207-223

LAU, A. T.-M. Continuity of Arens multiplication on the dual space of bounded uniformly continuous functions on locally compact groups and topological semigroups. 99 (1986) 273-283 
LEe, C.-S. \& Cochran, J. A. Inequalities related to Hardy's and Heinig's. 96 (1984) 1-7

Leinen, F. \& Phillips, R. E. Existentially closed central extensions of locally finite $p$-groups. 100 (1986) 281-301

LetTL, G. Finding fundamental units in algebraic number fields. 98 (1985) 383-388

Lewis, D. W. Periodicity of Clifford algebras and exact octagons of Witt groups. 98 (1985) 263-269

Lewis, L. G. The uniqueness of bundle transfers. 93 (1983) 87-111

LI, D. Indefinite binary forms representing the same numbers. 92 (1982) 29-33

Lichtman, A. I. Localization in enveloping algebras. 93 (1983) 467-475

Lickorish, W. B. R. A relationship between link polynomials. 100 (1986) 109-112

Light, W. A. \& Halton, E. J. Minimal projects in $L_{p}$-spaces. 97 (1985) 127-136

LiNes, D. On even-dimensional fibred knots obtained by plumbing. 100 (1986) 117-131

LiPSon, A. S. An evaluation of a link polynomial. 100 (1986) 361-364

LitTLE, G. Asymptotic estimates of the eigenvalues of certain positive Fredholm operators. (1982) 267-284

Eigenvalues of positive integral operators with certain entire kernels. 99 (1986) 535-545

Livingston, C. More 3-manifolds with multiple knot-surgery and branched-cover descriptions. 91 (1982) 473-475

Inequivalent bordant group actions on a surface. 99 (1986) 233-238

LLOYd, N. G. \& Blows, T. R. The number of small-amplitude limit cycles of Liénard equations. 95 (1984) 359-366

Long, D. D. Strongly plus-amphicheiral knots are algebraically slice. 95 (1984) 309-312

A note on the normal subgroups of mapping class groups. 99 (1986) 79-87

Lorenz-Petzold, D. The general vacuum Bianchi type-V solution in the Brans-Dicke theory. 95 (1984) 175-178

Exact Brans-Dicke-Bianchi type-V solutions. 96 (1984) 183-189

Exact anisotropic solutions of $d=11$ supergravity. 98 (1985) $187-190$

LORIMER, P. J. .Corrigenda: On projective planes of type $(6, m) . \quad 93(1983) 379-382$

Love, E. R. Inequalities related to those of Hardy and of Cochran and Lee. 99 (1986) 395-408

Love, E. R. \& Byrne, A. Real inversion theorems for generalized Stieltjes transforms. II. 92 (1982) 275-291

Lozano, M. T. Arcbodies. 94 (1983) 253-260

Lozano, M. T. \& Przytycki, J. H. Incompressible surfaces in the exterior of a closed 3-braid. I. Surfaces with horizontal boundary components. 98 (1985) 275-299

LubotZKY, A. \& HARAN, D. Maximal abelian subgroups of free profinite groups. 97 (1985) 51-55

Lusztia, G. \& Alvis, D. On Springer's correspondence for simple groups of type $E_{n}(n=6,7,8)$. $92(1982) 65-78$

Lyons, T. \& BanNeTt, C. Stopping non-commutative processes. 99 (1986) 151-161

MaCbeath, A. M. \& Baskan, T. Centralizers of reflections in crystallographic groups. 92 (1982) $79-91$

MACKAY, R. S. \& Tresser, C. Badly ordered orbits of circle maps. 96 (1984) 447-451

MACLACHLAN, C. On the structure of certain arithmetic subgroups of $S L_{2}(R) . \quad 97(1985)$ 211-217

Maclachlan, C. \& Rosenberger, G. Two-generator arithmetic Fuchsian groups. 93 (1983) 383-391

MCCarthy, P. J. Projective actions, invariant sigma-curves and quadratic functional equations. 98 (1985) 195-212

MoCarthy, P. J., Crampin, M. \& Stephenson, W. Graphs in the plane invariant under an area preserving linear map and general continuous solutions of certain quadratic functional equations. 97 (1985) 261-278

McCloskey, J. P. Characterizations of $r$-potent matrices. 96 (1984) 213-222

McClure, J. E. \& SNaith, V. P. On the $K$-theory of the extended power construction. 92 (1982) 263-274

McCrudden, M. Infinitely divisible probabilities on SL $(2, \mathbb{C})$ are continuously embedded. 92 (1982) 101-107

On the supports of Gauss measures on algebraic groups. 96 (1984) 437-445

MoDiarmid, C. Achromatic numbers of random graphs. 92 (1982) 21-28

McGibBon, C. A. $K$-theory and finite loop spaces of rank one. 99 (1986) 481-487 
McIsaAc, A.J. Some conditions for finite presentation of nilpotent-by-abelian groups. (1984) 411-415

McMulles, P. The volume of certain convex sets. 91 (1982) 91-97

McPolin, P. T. N. \& Wickstead, A. W. The order boundness of band preserving operators on uniformly complete vector lattices. 97 (1985) 481-487

MAdan, S. \& SJögren, P. Poisson integrals of absolutely continuous and other measures. 95 (1984) 141-147

MAdDEN, J. \& VeRmeER, J. Lindelöf locales and realcompactness. 99 (1986) 473-480

MADDox, I. J. FK spaces which include strongly summable sequences. 93 (1983) 131-134

Series in locally convex spaces and inclusions between FK spaces. 95 (1984) 467-472

Sequence spaces defined by a modulus. 100 (1986) 161-166

MAddox, I. J. \& KuTtNer, B. Lacunary theorems for Cesàro means. 93 (1983) 231-235

MaEjima, M. \& MORI, T. Some renewal theorems for random walks in multidimensional time. 95 (1984) 149-154

Maejima, M. \& Van Assche, W. Probabilistic proofs of asymptotic formulas for some classical polynomials. $97(1985) 499-510$

MagnUS, R. J. Some properties of wild orbits of infinite-dimensional transformation groups. 92 (1982) 429-435

Mahowald, M. \& Davis, D. M. The spectrum $(P \wedge b o)_{-\infty} .96(1984) 85-93$

MALLER, R. A. Asymptotic normality of lightly trimmed means - a converse. 92 (1982) 535-545

MANDaL, B. N. \& Goswami, S. K. Scattering of surface waves obliquely incident on a fixed half immersed circular cylinder. 96 (1984) 359-369

Mansfield, A. Determining the thickness of graphs is NP-hard. 93 (1983) 9-23

Marshall, B. P. \& DRURY, S. W. Fourier restriction theorems for curves with affine and Euclidean arclengths. 97 (1985) 111-125

Marstrand, J. M., Grimmett, G. R. \& Keane, M. On the connectedness of a random graph. 96 (1984) 151-166

Martin, N. Corrigenda: Cobordism of homology manifolds. 92 (1982) 375-378

Corrigenda: Transverse regularity for maps of homology manifolds. 92 (1982) 379

Mason, D. M. \& Csörgö, S. Central limit theorems for sums of extreme values. 98 (1985) $547-558$

MASon, J. R. M. On the maximum sizes of certain $(k, n)$-ares in finite projective geometries. 91 (1982) 153-169

Mason, R. C. The hyperelliptic equation over function fields. 93 (1983) 219-230

Norm form equations. III : positive characteristic. 99 (1986) 409-423

Masser, D. W. \& Brownawell, W. D. Vanishing sums in function fields. 100 (1986) 427-434

MathaI, A. M. \& ANDerson, W.J. Various representations of a generalized hypergeometric function through statistical techniques. 96 (1984) $325-330$

Mathias, A. R. D. Unsound ordinals. $96(1984) 391-411$

Mathias, A. R. D. \& Henle, J. M. Supercontinuity. 92 (1982) 1-15

Matrila, K. Complex strict and uniform convexity and hyponormal operators. 96 (1984) $483-493$

MAY, J. P. \& TAYLOR, L. R. Generalized splitting theorems. 93 (1983) 73-86

Meaney, C. On almost everywhere convergent eigenfunction expansions of the Laplace-Beltrami operator. 92 (1982) 129-131

Medgalchi, A. R. \& Ghahramani, F. Compact multipliers on weighted hypergroup algebras. 98 (1985) 493-500

Compact multipliers on weighted hypergroup algebras. II. 100 (1986) 145-149

Melvin, P. Tori in the diffeomorphism groups of simply-connected 4-manifolds. 91 (1982) 305-314

Merikoski, J. K., Virtanen, A. \& Hyyrö, S. Improving certain simple eigenvalue bounds. 99 (1986) 507-518

Micchell, C. A., Smith, P. W. \& Dahmen, W. Asymptotically optimal sampling schemes for periodic functions. 99 (1986) 171-177

Miller, A. W. \& Kunen, K. Borel and projective sets from the point of view of compact sets. $94(1983) 399-409$

MilletT, K. \& Rolfsen, D. A theorem of Borsuk-Ulam type for Seifert-fibred 3-manifolds. 100 (1986) 523-532 
Milnes, P. On Bohr almost periodicity. 99 (1986) 489-493

Mislin, G. \& Friedlander, E. M. Locally finite approximation of Lie groups. $11 . \quad 100$ (1986) $505-517$

Mitchell, W. J. The core model for sequences of measures. I. 95 (1984) 229-260

Mitchell, W. J. R. General position properties of ANR's. 92 (1982) 451-466

A characterization of piecewise linear homology manifolds. 93 (1983) 271-274

MoerdiJk, I. \& Reyes, G. E. De Rham's theorem in a smooth topos. 96 (1984) 61-71

Mohapatra, R. N., Kuttner, B. \& Sahney, B. N. Saturation results for a class of linear operators. 94 (1983) 133-148

Mond, D. On the tangent developable of a space curve. 91 (1982) 351-355

Montesinos, J. M. Representing 3-manifolds by a universal branching set. 94 (1983) 109-123

Montiel, S. \& Romero, A. Holomorphic sectional curvatures of indefinite complex Grassmann manifolds. 93 (1983) 121-125

Complex Einstein hypersurfaces of indefinite complex space forms. 94 (1983) 495-508

Moran, W. \& Brown, G. Probability measures with trivial Stam groups. 91 (1982) 477-484

Moran, W. \& CAREY A. L. Characters of nilpotent groups. 96 (1984) 123-137

Moran, W., Cooke, R. M. \& Keane, M. An elementary proof of Gleason's theorem. 98 (1985) $117-128$

Mori, T. On the limit distributions of lightly trimmed sums. 96 (1984) 507-516

MoRI, T. \& MaEJima, M. Some renewal theorems for random walks in multidimensional time. 95 (1984) 149-154

Morris, A. O. \& YASEen, A. K. Some combinatorial results involving shifted Young diagrams. 99 (1986) 23-31

Morris, S. A., Katz, E. \& Nickolas, P. Free subgroups of free abelian topological groups. 100 (1986) 347-353

Morton, H. R. An irreducible 4-string braid with unknotted closure. 93 (1983) 259-261

Alexander polynomials of closed 3-braids. 96 (1984) 295-299

Seifert circles and knot polynomials. 99 (1986) $107-109$

Threading knot diagrams. 99 (1986) 247-260

Moskowitz, M. Uniform boundedness for non-abelian groups. 97 (1985) 107-110

MUnN, W. D. On commutative semigroup algebras. 93 (1983) 237-246

On the Jacobson radical of certain commutative semigroup algebras. 96 (1984) 15-23

Murasugr, $K$. On the Arf invariant of links. 95 (1984) 61-69

Murchiston, G. S. \& Stanley, M. G. A ' $T_{1}$ ' space with no closed points, and a " $T_{1}$ " locale which is not ' $T_{1}$ '. $95(1984) 421-422$

Nazarov, V. U. Time-dependent variational principle and self-consistent field equations. 98 (1985) 373-379

Neisendorfer, J. A. \& Cohen, F. R. Note on desuspending the Adams map. 99 (1986) 59-64

NeSTORIDIS, V. Averages of holomorphic mappings. 100 (1986) 371-381

Newstead, P. E. Quadratic complexes. II. 91 (1982) 183-206

NGô VIÊt Trung. Absolutely superficial sequences. 93 (1983) 35-47

Nicas, A. J. On $\mathrm{Wh}_{3}$ of a Bieberbach group. 95 (1984) 55-60

An infinite family of non-Haken hyperbolic 3-manifolds with vanishing Whitehead groups. 99 (1986) 239-246

Nicas, A. J. \& StaRK, C. W. Whitehead groups of certain hyperbolic manifolds. 95 (1984) 299-308

Nickolas, P., Morris, S. A. \& Katz, E. Free subgroups of free abelian topological groups. 100 (1986) 347-353

Nowak, W. G. On the average order of the lattice rest of a convex planar domain. 98 (1985) $1-4$

NowıŃski, K. S. Unitary bordisms with singularities determined by a $U^{*}$-complex. 95 (1984) 443-456

Nurcombe, J. R. A note on the strong regularity of Nörlund means. 94 (1983) 261-263

Nwoкан, O. D. I. Composite matrix inverses and generalized Gershgorin sets. 95 (1984) 267-276

O'Carroll, L. \& Qureshi, M. A. Primary rings and tensor products of algebras. 92 (1982) 41-48 
Odlyzko, A. M. \& FlaJolet, P. Limit distributions for coefficients of iterates of polynomials with applications of combinatorial enumerations. 96 (1984) 237-253

Odoni, R. W. K. Trigonometric sums of Heilbronn's type. 98 (1985) 389-396

A note on trigonometric sums in several variables. 99 (1986) 189-193

Ogомa, T. Fibre products of Noetherian rings and their applications. 97 (1985) 231-241

Ојна, A. \& Dikshiт, H. P. On convergence and quasiconformality of complex planar spline interpolants. $99(1986) 347-356$

OkNıśski, J. On the radical of semigroup algebras satisfying polynomial identities. 99 (1986) 45-50

OKNIŃski, J. \& W AUTERS, P. Radicals of semigroup rings of commutative semigroups. 99 (1986) 435-445

Olver, P. J. Conservation laws and null divergences. 94 (1983) 529-540

Conservation laws and null divergences. II. Non-negative divergences. 97 (1985) 511-514

Oмey, E. \& Embrechts, P. On subordinated distributions and random record processes. 93 (1983) 339-353

Orbanz, U. Transversal parameters and tangential flatness. 98 (1985) 37-49

Orbanz, U. \& Herrmann, M. On equimultiplicity. 91 (1982) 207-213

Oshima, H. Some James numbers of Stiefel manifolds. 92 (1982) 139-161

OXLEY, J. G. Threshold distribution functions for some random representable matroids. 95 (1984) 335-347

OXLEY, J. G. \& Kelly, D. G. Asymptotic properties of random subsets of projective spaces. $91(1982) 119-130$

Palka, Z. Extreme degrees in random subgraphs of regular graphs. 97 (1985) 69-78

Some remarks about extreme degrees in a random graph. 100 (1986) 167-174

PaRÉ, R. A topos with no geometric morphism to any Boolean one. 97 (1985) 397

Parsons, D. J. The centre of the second dual of a commutative semigroup algebra. 95 (1984) 71-92

Abelian semigroups whose Stone-Cech compactifications have left ideal decompositions. 97 (1985) 473-479

Partington, J. R. On nearly uniformly convex Banach spaces. 93 (1983) 127-129

Corrigenda: On nearly uniformly convex Banach spaces. 94 (1983) 189

Growth conditions on subharmonic functions and resolvents of operators. 97 (1985) 321-324

Partington, J. R. \& Istráţescu, V. I. On nearly uniformly convex and $k$-uniformly convex spaces. 95 (1984) 325-327

Pascual-Gainza, $P$. On the simple object associated to a diagram in a closed model category. 100 (1986) 459-474

Patterson, S. J. Tori in metaplectic covers of $G L_{2}$ and applications to a formula of LoxtonMatthews. 100 (1986) 249-263

Peligrad, C., Goodman, F. M. \& Jorgensen, P. Smooth derivations commuting with Lie group actions. 99 (1986) 307-314

Pengelley, D. J. \& Giambalvo, V. The homology of MSpin. 95 (1984) 427-436

Perraud, J. \& Collins, D. J. Cohomology and finite subgroups of small cancellation quotients of free products. 97 (1985) 243-259

Petkov, V. Inverse scattering problem for transparent obstacles. 92 (1982) 361-367

Petrich, M. \& Fountain, J. Brandt semigroups of quotients. 98 (1985) 413-426

Petrie, T. Smith equivalence of representations. 94 (1983) 61-99

Phillips, R. E. \& LeInen, F. Existentially closed central extensions of locally finite $p$-groups. 100 (1986) 281-301

Pinch, R. G. E. Elliptic curves with good reduction away from 2. 96 (1984) 25-38

a-convexity. $\quad 97$ (1985) 63-68

A sequence well distributed in the square. 99 (1986) 19-22

Elliptic curves with good reduction away from 2 . II. 100 (1986) 435-457

Pini, R. \& GaUdRY, G. I. Bernstein's theorem for compact, connected lie groups. 99 (1986) 297-305

Pittel, B. On the probable behaviour of some algorithms for finding the stability number of a graph. 92 (1982) 511-526

Pizer, A. Hermitian character and the first problem of R. H. Fox. 98 (1985) 447-458 
Plotnick, S. P. Infinitely many disk knots with the same exterior. 93 (1983) 67-72

Polyrakis, I. A. Lattice Banach spaces order-isomorphic to $l_{1} .94$ (1983) 519-522

Extreme points of unbounded, closed and convex sets in Banach spaces. 95 (1984) 319-323

Porter, D. On some Cauchy-separable integral equations. 99 (1986) 547-564

The reduction of a pair of singular integral equations. 100 (1986) 175-182

Porter, T. \& Cordier, J.-M. Vogt's theorem on categories of homotopy coherent diagrams. 100 (1986) 65-90

Priddy, S. B. \& Kunn, N. J. The transfer and Whitehead's conjecture. 98 (1985) 459-480

Pride, S. J. \& Howie, J. The word problem for one-relator semigroups. 99 (1986) 33-44

PrIKRY, K. \& JECH, T. Cofinality of the partial ordering of functions from $\omega_{1}$ into $\omega$ under eventual domination. 95 (1984) 25-32

Przytycki, J. H. \& Lozano, M. T. Incompressible surfaces in the exterior of a closed 3-braid. I. Surfaces with horizontal boundary components. 98 (1985) 275-299

Puri, M. L. \& Ralescu, D. A. Limit theorems for random compact sets in Banach space. 97 (1985) 151-158

Putinar, M. \& BĂNiČ̆, C. On complex vector bundles on rational threefolds. 97 (1985) 279-288

QUÁCH THI CÂM VÂN On a theorem on partially summing tangles by Lickorish. 93 (1983) 63-66

QUReshi, M. A. \& O'CARroll, L. Primary rings and tensor products of algebras. 92 (1982) $41-48$

Radcliffe, J., Rass, L. \& Stirling, W. D. Wave solutions for the deterministic host-vector epidemic. 91 (1982) 131-152

Raina, R. K. \& Srivastava, H. M. Some combinatorial series identities. 96 (1984) 9-13

RAKA, M. Inhomogeneous minimum of indefinite quadratic forms in six variables: a conjecture of Watson. 94 (1983) 1-8

On a conjecture of Watson. 94 (1983) 9-22

Ralescu, D. A. \& Puri, M. L. Limit theorems for random compact sets in Banach space.

97 (1985) 151-158

RAMSEY, T. \& WeIT, Y. Mean values and classes of harmonic functions. 96 (1984) 501-505

RANkin, R. A. Fourier coefficients of cusp forms. 100 (1986) 5-29

RANSFORD, T. J. A short elementary proof of the Bishop-Stone-Weierstrass theorem. 96 (1984) $309-311$

Rass, L., Stirling, W. D. \& Radcliffe, J. Wave solutions for the deterministic host-vector epidemic. 91 (1982) 131-152

RATLifF, L. J. Note on analytic spread and asymptotic sequences. 93 (1983) 49-55

Ratliff, L. J. \& KATz, D. Form rings and projective equivalance. 99 (1986) 447-456

RAWNSLEY, J. H. On the rank of horizontal maps. 92 (1982) 485-488

READE, J. B. Eigen-values of Lipschitz kernels. 93 (1983) 135-140

Eigenvalues of smooth kernels. 95 (1985) 135-140

REDDY, B. D. Surface instabilities on an equibiaxially stretched elastic half-space. 91 (1982) 491-501

REES, D. A note on asymptotically unmixed ideals. 98 (1985) 33-35

Rennie, B. C. \& Burkill, H. Almost periodic generalized functions. 94 (1983) 149-166

ReYeS, G. E. \& MoerdiJK, I. De Rham's theorem in a smooth topos. 96 (1984) 61-71

RHOADES, B. E. Matrix summability of Fourier series based on inclusion theorems. $\quad 100$ (1986) 545-557

Rhodes, F. The role of the principal part in factorizing block maps. 96 (1984) 223-235

Rhodes-Robinson, P. F. Note on the reflexion of water waves at a wall in the presence of surface tension. 92 (1982) 369-373

RICE, J. W. \& DooleY, A. H. Contractions of rotation groups and their representations. 94 (1983) 509-517

RICKER, W. Spectral representation of local semigroups associated with Klein-Landau systems. 95 (1984) 93-100

Semigroups of operators and an application to spectral theory. 96 (1984) 143-149

Riedel, N. On the Dixmier property of simple $C^{*}$-algebras. 91 (1982) 75-78

Rionero, S., Galdi, G. P. \& Knops, R. J. Uniqueness and continuous dependence in the linear elastodynamic exterior and half-space problems. 99 (1986) 357-366 
Rippon, P. J. A boundary estimate for harmonic functions. 91 (1982) 79-90

ROBERTS, R.S. Molecular symmetry and multiconfiguration methods based on the Brillouin theorem. 97 (1985) 551-570

Robertson, A. G. Schwarz inequalities and the decomposition of positive maps on $C^{*}$-algebras. 94 (1983) 291-296

Robertson, M. M. \& ZuCKer, I. J. Further aspects of the evaluation of $\Sigma_{(m, n \neq 0,0)}$ $\left(a m^{2}+b n m+c n^{2}\right)^{-8} .95(1984) 5-13$

Rodriguez Palacios, A. \& Cuenca Mira, J. A. Isomorphisms of $H^{*}$-algebras. 97 (1985) 93-99

RohrLich, D. E. A modular version of Jensen's formula. 95 (1984) 15-20

Rolfsen, D. \& MilletT, K. A theorem of Borsuk-Ulam type for Seifert-fibred 3-manifolds. 100 (1986) 523-532

Romero, A. \& Montiel, S. Holomorphic sectional curvature of indefinite Grassmann manifolds. 93 (1983) 121-125

Complex Einstein hypersurfaces of indefinite complex space forms. 94 (1983) 495-508

Rose, L. R. F. Asymptotic analysis of the Cooke-Noble integral equation. 92 (1982) 293-306

Rosenberger, G. \& Maclachlan, C. Two-generator arithmetic Fuchsian groups. 93 (1983) 383-391

RosickÝ, J. \& Śmarda, B. $\quad T_{1}$-locales. 98 (1985) 81-86

Rothschild, B., RUCiński, A. \& GYöRI, E. Every graph is contained in a sparsest possible balanced graph. 98 (1985) 397-401

Ruberman, D. Imbedding four-manifolds and slicing links. 91 (1982) 107-110

Ruciński, A., Rothschild, B. \& GYöRI, E. Every graph is contained in a sparsest possible balanced graph. 98 (1985) 397-401

RUCKLE, W. H. Absolutely divergent series and classes of Banach spaces. 94 (1983) 281-289

Ruckle, W. H. \& Fourie, J. H. Projections and embeddings of locally convex operator spaces and their duals. 96 (1984) 321-323

Rudraiah, N. \& Shivaraya, E. S. On the interaction between Tollmien-Schlichting and Rayleigh-Bénard instabilities in the presence of a longitudinal magnetic field. 93 (1983) 355-377

RusH, D. E. An arithmetic characterization of algebraic number fields with a given class group. 94 (1983) 23-28

RUtTER, J. W. The group of homotopy self-equivalance classes of $C W$ complexes. 93 (1983) 275-293

Rüttimann, G. T. \& Edwards, C. M. On the facial structure of the units balls in a $G L$-space and its dual. 98 (1985) 305-322

Ryan, J. Properties of isolated singularities of some functions taking values in real Clifford algebras. 95 (1984) 277-298

SAAB, P. Weakly compact, unconditionally converging, and Dunford-Pettis operators on spaces of vector-valued continuous functions. 95 (1984) 101-108

SaAB, P. \& TaLAgrand, M. A Choquet theorem for general subspaces of vector-valued functions. 98 (1985) 323-326

Sahney, B. N., Kuttner, B. \& Mohapatra, R. N. Saturation results for a class of linear operators. 94 (1983) 133-148

Sankaran, G. K. Effective resolution of cusps on Hilbert modular varieties. 99 (1986) 51-57

Saracino, D., Wood, C. \& Glass, A. M. W. Non-amalgamation of ordered groups. 95 (1984) 191-195

Sarantopoulos, I. Estimates for polynomial norms on $L^{p}(\mu)$ spaces. 99 (1986) 263-271

Sarlet, W., Cantrijn, F. \& Crampin, M. Higher-order differential equations and higher-order lagrangian mechanics. 99 (1986) 565-587

Sčedrov, A. \& Friedman, H. M. On the quantificational logic of intuitionistic set theory. 99 (1986) 5-10

SCHAEFFER, D. G. \& BALL, J. M. Bifurcation and stability of homogeneous equilibrium configurations of an elastic body under dead-load tractions. 94 (1983) 315-339

Schafir, R. L. The Variational Principle and natural transformations. II. Time dependent theory. 91 (1982) 331-341

Schenzel, P. Cohomological annihilators. 91 (1982) 345-350

The parametric blowing-up of two-dimensional local domains. 94 (1983) 217-228

15 
Schofield, A. H. Artin's problem for skew field extensions. 97 (1985) 1-6

Schofield, A. H. \& CohN, P. M. On the law of nullity. 91 (1982) 357-374

Scholl, A. J. Fourier coefficients of Eisenstein series on non-congruence subgroups. 99 (1986) 11-17

Scott, D. J. \& Huggins R. M. A law of the iterated logarithm for weakly exchangeable arrays. 98 (1985) 541-545

Sealey, H. C. J. Some conditions ensuring the vanishing of harmonic differential forms with applications to harmonic maps and Yang-Mills theory. 91 (1982) 441-452

SeELy, R. A. G. Locally cartesian closed catagories and type theory. 95 (1984) 33-48

SELICK, P. On conjectures of Moore and Serre in the case of torsion-free suspensions. 94 (1983) 53-60

Seshagiri Rao, K. V. V., Sree Hari Ra0, V. \& Erbe, L. H. Non-oscillation and asymptotic properties for a class of forced second-order nonlinear equations. 95 (1984) 155-163

Seweryński, M. \& Kalinowski, M. W. Differential equation for Hermite-Bell polynomials. 91 (1982) 259-265

ShaCkELL, J.R. Continuation of analytic structure in the maximal ideal space of a uniform algebra. 92 (1982) 437-449

Shahabi Shojaei, M. A. \& Hartley, B. Finite groups of matrices over division rings. 92 (1982) $55-64$

Finite quasisimple groups of $2 \times 2$ matrices over a division ring. 97 (1985) $415-420$

Sharp, R. Y. \& ZAKERI, H. Generalized fractions, Buchsbaum modules and generalized CohenMacaulay modules. 98 (1985) 429-436

Sheil-Small, T. On the Fourier series of a finitely described convex curve and a conjecture of H. S. Shapiro. 98 (1985) 513-527

Shivaraya, E. S. \& Rudraiah, N. On the interaction between Tollmien-Schlichting and Rayleigh-Bénard instabilities in the presence of a longitudinal magnetic field. 93 (1983) 355-377

Shorey, T. N. Perfect powers in values of certain polynomials at integer points. 99 (1986) 195-207

Short, H. \& González Acuña, F. Knot surgery and primeness. 99 (1986) 89-102

SiddiqI, J. A. A criterion for the $(e, c)$-summability of Fourier series. 92 (1982) 121-127

Silverman, J. H. The $S$-unit equation over function fields. 95 (1984) 3-4

Silverman, J. H. \& Evertse, J. H. Uniform bounds for the number of solutions to $Y^{n}=f(X)$. 100 (1986) 237-248

Singer, M. A. Duality in twistor theory without Minkowski space. 98 (1985) 591-600

Sivaloganathan, J. A field theory approach to stability of radial equilibria in nonlinear elasticity. 99 (1986) 589-604

Sjögren, P. \& Madan, S. Poisson integrals of absolutely continuous and other measures. 95 (1984) 141-147

Sloane, N. J. A. \& Conway, J. H. The Coxeter-Todd lattice, the Mitchell group, and related sphere packings. 93 (1983) 421-440

SMall, C. G. Random uniform triangles and the alignment problem. 91 (1982) 315-322

A classification theorem for planar distributions based on the shape statistics of independent tetrads. 96 (1984) 543-547

Small, L. W., Stafford, J. T. \& WARfield, R. B. Affine algebras of Gelfand-Kirillov dimension one are PI. 97 (1985) 407-414

SMarda, B. \& RoskickÝ, J. T,-locales. 98 (1985) 81-86

Sмiтh, L. Transfer and ramified coverings. 93 (1983) 485-493

Smith, M. K. \& Gilchrist, M. P. Non-commutative UFD's are often PID's. 95 (1984) 417-419

Sмiтн, P. F. Some examples of maximal orders. 98 (1985) 19-32

Smith, P. W., Dahmen, W. \& Micchelli, C. A. Asymptotically optimal sampling schemes for periodic functions. 99 (1986) 171-177

SмIтн, S. P. Krull dimension of factor rings of the enveloping algebra of a semi-simple Lie algebra. 93 (1983) 459-466

SNaITH, V. P. \& McClure, J. E. On the $K$-theory of the extended power construction. 92 (1982) 263-274

Soares, M. G. \& Giblin, P. J. Recognizing singularities of surfaces in $\mathbb{C}^{3}$. 91 (1982) 17-27

SorI, M. A. Some criteria for nuclearity. 100 (1986) 151-159 
Soma, T. Hyperbolic, fibred links and fibre-concordances. 96 (1984) 283-294

Soomro, K. D. \& Jones, G. A. On a theorem of Wielandt concerning simply primitive groups. 92 (1982) 419-423

Spouge, J. L. An existence theorem for the discrete coagulation-fragmentation equations. 96 (1984) 351-357

An existence theorem for the discrete coagulation-fragmentation equations. II. Inclusion of source and efflux terms. 98 (1985) 183-185

Sree Hari Rao, V., Erbe, L. H. \& Seshagiri Rao, K. V. V. Non-oscillation and asymptotic properties for a class of forced second-order nonlinear equations. 95 (1984) 155-163

Srivastava, H. M. \& Buschman, R. G. Series identities and reducibility of Kampé de Fériet functions. $91(1982) 435-440$

Srivastava, H. M. \& Raina, R. K. Some combinatorial series identities. 96 (1984) 9-13

Stafford, J. T. Homological properties of the enveloping algebra $U\left(S l_{2}\right)$. 91 (1982) 29-37

StafFord, J. T., WARFIELD, R. B. \& SMALL, L. W. Affine algebras of Gelfand-Kirillov dimension one are PI. 97 (1985) 407-414

Stanley, M. G. \& Murchiston, G. S. A ' $T_{1}$ ' space with no closed points, and a " $T_{1}$ " locale which is not ' $T T_{1}$ '. 95 (1984) 421-422

Stansfield, S. E., Stroughair, J. D., Bona, J. L., Bennett, D. P. \& Brown, R. W. The stability of internal solitary waves. 94 (1983) 351-379

StaRK, C. W. \& NicAS, A. J. Whitehead groups of certain hyperbolic manifolds. 95 (1984) $299-308$

Steiner, R. The relative Mayer-Vietoris sequence. 95 (1984) 423-425

Stephenson, W., McCarthy, P. J. \& Crampin, M. Graphs in the plane invariant under an area preserving linear map and general continuous solutions of certain quadratic functional equations. 97 (1985) 261-278

Stewart, I. \& WoodCock, A. Bifurcation and hysteresis varieties for the thermal-chainbranching model. II : positive modal parameter. 96 (1984) 331-349

Stirling, W. D., Radcliffe, J. \& Rass, L. Wave solutions for the deterministic host-vector epidemic. 91 (1982) 131-152

Stoltzfus, N. W. \& Bayer-Fluckiger, E. Indecomposable knots and concordance. 93 (1983) 495-502

Streater, R. F., Wilde, I. F. \& Barnett, C. Stochastic integrals in an arbitrary probability gauge space. $94(1983) 541-551$

StRICKLAND, P. Knots which are branched cyclic covers of only finitely many knots. 98 (1985) 301-304

Stroughair, J. D., Bona, J. L., Bennett, D. P., Brown, R. W. \& Stansfield, S. E. The stability of internal solitary waves. 94 (1983) 351-379

SucıU, A. I. Infinitely many ribbon knots with the same fundamental group. 98 (1985) 481-492

SUKLA, I. L. \& KuTtN ER, B. On $(\mathscr{D}, h(n))$ summability methods. 97 (1985) 189-193

Szücs, A. Multiple points of singular maps. $100(1986) 331-346$

TAHARA, K.-I. Augmentation quotients and dimension subgroups of semidirect products. 91 (1982) 39-49

TAKAČI, A. A note on the distributional Stieltjes transformation. 94 (1983) 523-527

TALAGRAND, M. \& SAAB, P. A Choquet theorem for general subspaces of vector-valued functions. 98 (1985) 323-326

Tang, C. Y. \& Allenby, R. B. J. T. Residual finiteness of certain 1-relator groups: extensions of results of Gilbert Baumslag. 97 (1985) 225-230

TARnaI, T. \& Gáspár, Zs. Improved packing of equal circles on a sphere and rigidity of its graph. 93 (1983) 191-218

Tassa, U. \& Fraenkel, A. S. Strategies for compounds of partizan games. 92 (1982) 193-204

TAYLOR, L. R. \& MAY, J. P. Generalized splitting theorems. 93 (1983) 73-86

TAYLOR, M. J. Relative Galois module structure of rings of integers and elliptic functions. 94 (1983) 389-397

TAYLOR, S. J. The measure theory of random fractals. 100 (1986) 383-406

TaYlor, S. J. \& Tricot, C. The packing measure of rectifiable subsets of the plane. 99 (1986) 285-296

Taylor, S. J. \& Watson, N. A. A Hausdorff measure classification of polar sets for the heat equation. 97 (1985) 325-344 
Tenenbaum, G. \& Bingham, N. H. Reisz and Valiron means and fractional moments. 99 (1986) $143-149$

Tezuka, M. \& Y Agita, N. The varieties of the $\bmod p$ cohomology rings of extra special $p$-groups for an odd prime $p .94$ (1983) 449-459

Thomas, E. \& Vasquez, A. T. A family of elliptic curves and cyclic cubic field extensions. 96 (1984) 39-43

Tномаson, A. G. An extremal function for contractions of graphs. 95 (1984) 261-265

Thompson, G. \& Crampin, M. Affine bundles and integrable almost tangent structures. 98 (1985) 61-71

ToD, K. P. The singularities of $\mathscr{H}$-space. 92 (1982) 331-347

ToD, K. P. \& EASTwOod, M. G. Edth - a differential operator on the sphere. 92 (1982) 317-330

Toland, J.F. A necessary geometric condition for the existence of certain homoclinic orbits. 100 (1986) 591-594

Tonge, A. M. Polarization and the two-dimensional Grothendieck inequality. 95 (1984) 313-318

Towers, D. A. Corrigenda: Lattice isomorphisms of Lie algebras. 95 (1984) 511-512

Trace, B. A note concerning Seifert manifolds for 2-knots. 100 (1986) 113-116

Tresser, C. \& MACKAY, R. S. Badly ordered orbits of circle maps. 96 (1984) 447-451

Tricot, C. Two definitions of fractional dimension. 91 (1982) 57-74

A new proof for the residual set dimension of the apollonian packing. 96 (1984) 413-423

Tricot, C. \& Davies, R. O. A theorem about countable decomposability. 91 (1982) 457-458

TRICOT, C. \& TAYLOR, S. J. The packing measure of rectifiable subsets of the plane. 99 (1986) 285-296

Truss, J. K. The group of the countable universal graph. 98 (1985) 213-245

Tsarpalias, A. \& Argyros, S. A. Isomorphic embeddings of $l^{1}(\Gamma)$ into subspaces of $C(\Omega)^{*} .92$ (1982) 251-262

TsukiYama, K. Equivariant self equivalences of principal fibre bundles. 98 (1985) 87-92

Tu, G.-Z. On polynomial symmetries of the sine-Gordon equation. 91 (1982) 485-489

UPRETI, R. \& Joshi, J. M. C. A sequence of Gamma-type approximation operators. 96 (1984) $119-121$

UrSELL, F. Integrals with a large parameter: Hilbert transforms. 93 (1983) 141-149

Integrals with a large parameter: Legendre functions of large degree and fixed order. 95 (1984) 367-380

Van Assche, W. \& Maejima, M. Probabilistic proofs of asymptotic formulas for some classical polynomials. $97(1985) 499-510$

Vanhecke, L. \& Kowalski, O. Classification of five-dimensional naturally reductive spaces. 97 (1985) 445-463

VARopoulos, N. TH. Brownian motion can see a knot. 97 (1985) 299-309

VASERSTEIN, L. N. The subnormal structure of general linear groups. 99 (1986) 425-431

VASquez, A. T. \& Thomas, E. A family of elliptic curves and cyclic cubic field extensions. 96 (1984) $39-43$

Vasudevan, R. \& Goel, S. Embedding of quasi-multipliers of a Banach algebra into its second dual. 95 (1984) 457-466

VERMEER, J. \& MADDEN, J. Lindelöf locales and realcompactness. 99 (1986) 473-480

Virtanen, A., Hydrö, S. \& Merikoski, J. K. Improving certain simple eigenvalue bounds. 99 (1986) 507-518

Vogel, P. \& KWasik, S. On invariant knots. 96 (1984) $473-475$

WALL, C. T. C. Geometric invariant theory of linear systems. 93 (1983) 57-62

Pencils of real binary cubics. 93 (1983) 477-484

Determination of the semi-nice dimensions. 97 (1985) 79-88

Real forms of cusp singularities. 99 (1986) 213-232

Walsh, G. R. \& ARThURS, A. M. On Hammersley's minimum problem for a rolling sphere. 99 (1986) 529-534

WARfield, R. B., Small, L. W. \& Stafford, J. T. Affine algebras of Gelfand-Kirillov dimension one are PI. $97(1985) 407-414$ 
Watson, N. A. \& TAYLOR, S. J. A Hausdorff measure classification of polar sets for the heat equation. 97 (1985) 325-344

WaUters, P. \& OkniŃski, J. Radicals of semigroup rings of commutative semigroups. $\quad 99$ (1986) $435-445$

WeBER, N. C. Central limit theorems for a class of symmetric statistics. 94 (1983) 307-313

WEGMANN, S. A. \& Jones, J. D. S. Limits of stable homotopy and cohomotopy groups. 94 (1983) 473-482

Wehrfritz, B. A.F. Groups whose irreducible representations have finite degree. III. 91 (1982) $397-406$

Soluble-by-periodic skew linear groups. $96(1984)$ 379-389

WeISS, R. 3-transpositions in infinite groups. 96 (1984) 371-377

A uniqueness lemma for groups generated by 3-transpositions. 97 (1985) 421-431

WEIT, Y. \& RAMSEY, T. Mean values and classes of harmonic functions. 96 (1984) 501-505

Welsh, D. J. A. \& Donnelly, P. Finite particle systems and infection models. 94 (1983) $167-182$

Werner, N. M., Dorea, C. C. Y. \& David, H. T. Uniform $\epsilon$-independence and the convergence in distribution of randomly indexed sequences. 96 (1984) 533-542

WhELAN, C. T. On the calculation of cross-sections for electron neutral atom collisions in the Born approximation to the reactance matrix. 95 (1984) 179-186

White, A. T. Ringing the changes. 94 (1983) 203-215

Wickstead, A. W. \& McPolis, P. T. N. The order boundness of band preserving operators on uniformly complete vector lattices. 97 (1985) 481-487

Wilde, I. F., Barinett, C. \& Streater, R. F. Stochastic integrals in an arbitrary probability gauge space. $94(1983) 541-551$

Wilker, J. B. \& Beardon, A. F. The norm of a Möbius transformation. 96 (1984) 301-308

Williams, J. P. The join of several subnormal subgroups. 92 (1982) 391-399

Conditions for subnormality of a join of subnormal subgroups. 92 (1982) 401-417

Williams, K. A. J. \& Hunt, G. W. On truncation of the structural potential function. 95 (1984) 495-510

Williamson, J. H., Brown, G. \& Karanikas, C. The asymmetry of $M_{0}(G) .91(1982)$ 407-433

Williamson, J. H. \& Karanikas, C. Norms and spectra for certain subalgebras of $M(G)$. 95 (1984) 109-122

WILSON, B. J. Incompleteness of $(n q+n-q-2, n)$-arcs in finite projective planes of even order. 91 (1982) 1-8

Wilson, P. M. H. The components of $m K_{V}$ for threefolds with $\kappa(V)=0.97$ (1985) 437-443

A note concerning the global 2 -forms on a $\kappa=0$ threefold. 98 (1985) 191-193

WILSON, R. A. On maximal subgroups of the Fischer group $F i_{22} .95(1984)$ 197-222

The subgroup structure of the Lyons group. 95 (1984) 403-409

The maximal subgroups of the Lyons group. 97 (1985) 433-436

Wiseman, A. N. Projective modules over pullback rings. 97 (1985) 399-406

Wood, C., Glass, A. M. W. \& Saracino, D. Non-amalgamation of ordered groups. 95 (1984) $191-195$

WooD, J. C. Corrigenda: An extension theorem for holomorphic mappings. 94 (1983) 189

WoODCOCK, A. \& STEWART, I. Bifurcation and hysteresis varieties for the thermal-chainbranching model. II : positive modal parameter. 96 (1984) 331-349

Woonhouse, N. M. J. Vector bundles and complex polarizations. $92(1982) 489-509$

Wright, E. M. Corrigenda: A quadratic recurrence of Faltung type. 92 (1982) 379

WU, J.-M. G. Minimum growth of harmonic functions and thinness of a set. 95 (1984) 123-133

WU, Y.-Q. On the Arf invariant of links. $100(1986) 355-359$

Wulfsohn, A. Prime characteristic functions on compact separable groups. 96 (1984) 139-142

WürfEL, T. Extensions of pro-p groups of cohomological dimension two. 99 (1986) 209-211

Yagita, N. \& Tezuka, M. The varieties of the mod $p$ cohomology rings of extra special $p$-groups for an odd prime $p .94$ (1983) 449-459

YANG, J.S. \& BAGLEY, R. W. Semidirect products of central groups and groups with equal uniformities. 92 (1982) 239-241

Yaseen, A. K. \& Morris, A. O. Some combinatorial results involving shifted Young diagrams. 99 (1986) 23-31 
YIU, P. Y.H. Quadratic forms between spheres and the non-existence of sums of squares formulae. 100 (1986) 493-504

YUкıсн, J. E. The convolution metric $d_{g} .98$ (1985) 533-540

Zahreddine, Z. \& Fishel, B. Boundary conditions and reducibility of differential operators. $96(1984) 549-553$

ZAKERI, H. \& SHARP, R. Y. Generalized fractions, Buchsbaum modules and generalized CohenMacaulay modules. 98 (1985) 429-436

Zucker, I.J. \& Robertson, M. M. Further aspects of the evaluation of $\Sigma_{(m, n \neq 0,0)}$ $\left(a m^{2}+b n m+c n^{2}\right)^{-8} .95(1984) 5-13$ 


\section{The attention of authors is particularly directed to the following requests.}

1. Papers should be typed, double-spaced, on one side of white paper (of which A4, 210 by $297 \mathrm{~mm}$, is a suitable size). The pages must be numbered. Margins of $30 \mathrm{~mm}$ should be left at the side, top and bottom of each page. Two clear copies should be sent.

A cover page should give the title, the author's name and institution, with the address at which mail is to be sent.

The title, while brief, must be informative (e.g. A new proof of the prime-number theorem, whereas Some applications of a theorem of $G$. H. Hardy would be useless).

The first paragraph or two should form a summary of the main theme of the paper, providing an abstract intelligible to mathematicians.

For a typescript to be accepted for publication, it must aceord with the standard requirements of publishers, and be presented in a form in which the author's intentions regarding symbols ete. are clear to a printer (who is not a mathematician).

The following notes are intended to help the author in preparing the typescript. New authors may well enlist the help of senior colleagues, both as to the substance of their work and the details of setting it out eorrectly and attractively.

2. Notation

Notation should be chosen carefully so that mathematical operations are expressed with all possible neatness, to enlighten the task of the compositor and reduce the chance of error.

For instance $n_{k}(n$ sub $k)$ is common usage, but avoid if possible using $c \operatorname{sub} n \operatorname{sub} k$. Fractions are generally best expressed by a solidus. Complicated exponentials like

$$
\exp \left\{z^{2} \sin \theta /\left(1+y^{2}\right)\right\}
$$

should be shown in this and no other way.

In the manuscript, italies, small capitals and capitals are specified by single, double and triple underlinings. Bold-faced type is shown by wavy underlining; wavy will be printed wavy.

It helps if displayed equations or statements which will be quoted later are numbered in order on the right of their line. They ean then be referred to by, for example, 'from (7)'

The author must enable the printer (if necessary by pencilled notes in the margin) to distinguish between similar symbols such as $0,0,0,0,0 ; x, \mathrm{X}, \times ; \phi, \Phi, \varnothing ; 1,1 ; \epsilon, \epsilon ; \kappa, k$.

Greek letters can be denoted by $\mathrm{Gk}$ in the margin.

If an author wishes to mark the end of the proof of a theorem, the sign I may be used.

Footnotes should be avoided.

\section{Diagrams}

It is extremely helpful if diagrams are drawn in Indian ink on white eard, faintly blue or green-lined graph paper, or tracing cloth or paper. Symbols, legends and captions should be given on a transparent overlay. Each text figure must be numbered as Figure 1, Figure $2, \ldots$ and its intended position elearly indicated in the manuscript:

\section{Figure 1 here}

The author's name in pencil must be on all separate sheets of diagrams.

A figure is expensive to reproduce and should be included only when the subjeet matter demands it, or when it greatly elarifies the exposition.

The Society recognizes that some authors do not have the facilities for producing drawings of a sufficiently high standard to be reproduced directly and it is therefore willing to have such diagrams re-drawn, provided that they are clear.

\section{Tables}

Tables should be numbered (above the table) and set out on separate sheets. Indicate the position of each in the text as for figures:

\section{Table 3 here}

\section{References}

References should be collected at the end of the paper numbered in alphabetical order of the authors' names. Titles of journals should be abbreviated as in Mathematical Reviews. The following examples show the preferred style for references to a paper in a journal, a paper in a proceedings volume, a book and an unpublished dissertation:

[1] J. F. Ad a Ms. On the non-existence of elements of Hopf invariant one. Ann of Math. (2) 72 (1960), 20-104.

[2] M. P. Fourman and D. S. Scotr. Sheaves and logic. In Applications of Sheaves, Lecture Notes in Math. vol. 753 (Springer-Verlag, 1979), pp. 302-401.

[3] P. T. Jomnstone. Stone Spaces. Cambridge Studies in Advanced Math. no. 3 (Cambridge University Press, 1982).

[4] F. W. Lawvere. Functorial semantics of algebraic theories. Ph.D. thesis, Columbia University (1963) 


\section{Mathematical Proceedings of \\ the Cambridge Philosophical Society}

MPCPCO $102(P t$ I) I-I91 (1987) 0305-004I July I 987

\section{CONTENTS}

SOICHER, LeONaRd H. Presentations for Conway's group $\mathrm{Co}_{1} \quad$. . . . . . . . $\quad 1$

Соoк, R. J. \& Raghavan, S. Small independent zeros of quadratic forms . . . . . 5

Kleidman, Peter B. \& Wilson, Robert A. The maximal subgroups of $F i_{22}$. . . . 17

Baumslag, Girbert, Morgan, John W. \& Shalen, Peter B. Generalized triangle groups 25

LIEBECK, Martin W. The classification of finite simple Moufang loops . . . . . 33

Huскава, SAM. Reduction numbers for ideals of higher analytic spread . . . . . . 49

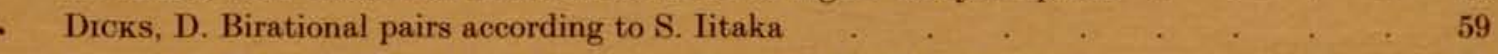

IsHIGURo, KensHI. Unstable Adams operations on classifying spaces _ . . . . . 71

Pizer, Adrian, Hermitian character and the first problem for R. H. Fox for links . $\quad$. 77

Huden, H. M., Lozano, M. T. \& Montesinos, J. M. Non-simple universal knots . 87

Gordon, C. McA. \& LuEoke, J. Only integral Dehn surgeries can yield reducible manifolds 97

KWASIK, SLAWOMIR. Low-dimensional concordances, Whitney towers and isotopies . $\quad 103$

SKWARCZYŃsKI, MACIEJ. Alternating projections between a strip and a halfplane _ . 121

SUEIRo, JUAN. A note on maximal operators of Hardy-Littlewood type . . . . . . 131

Kuttner, B. \& Parameswaran, M. R. A Tauberian theorem for Borel summability $\quad$ 135

JEFFERIES, Brian. Semigroups and diffusion processes _ . . . . . . . . . 139

Gopalsamy, K. A simple stability criterion for a linear system of neutral integro-differential equations . . . . . . . . . . . . . . . 149

WU, JANG-MEI. On heat eapacity and parabolic measure . . . . . . . . . 163

Bowman, S. A note on Hamiltonian structure . . . . . . . . . . . . . . . . 173

Corrigenda . . . . . . . . . . . . . . . . 191

(C) The Cambridge Philosophical Society 1987

CAMBRIDGE UNIVERSITY PRESS

THE PITT BUILDING, TRUMPINGTON STREET, CB2 IRP

32 EAST 57 TH STREET, NEW YORK, NY IOO22, USA

IO STAMFORD ROAD, OAKLEIGH, MELBOURNE 3 I 66, AUSTRALIA

Price $£ 19.50$ net (USA and Canada US \$46.00)

Subscription price $£ 53.00$ per volume ( $₫ 106.00$ per annum) net post free

(US $\$ 118.50$ per volume (US $\$ 237.00$ per annum) in USA and Canada)

Printed in Great Britain by the University Press, Cambridge 